\title{
Seismic Analysis of Low and High Rise Building Frames Incorporating Metallic Yielding Dampers
}

\author{
U. D. D. Liyanage*, T. N. Perera, H. Maneetes \\ Department of Civil Engineering, Asian Institute of Technology, Thailand
}

Copyright $\bigcirc 2018$ by authors, all rights reserved. Authors agree that this article remains permanently open access under the terms of the Creative Commons Attribution License 4.0 International License

\begin{abstract}
There are many passive energy dissipating devices designed to dissipate earthquake energy in a structure. Metallic yielding dampers is one of these devices which are very efficient as they dissipate seismic input energy through hysteretic behavior. This research used ETABS software to analyze the performance of three metallic yielding dampers; X-shaped damper, Double X-Shaped and Comb Teeth Damper. The storey response data obtained from the analysis is storey shear. Each damper has three types of material; A992 steel, A36 steel and Aluminium. Concentrically braced steel frames with Chevron bracing were used and the dampers were placed in brace to beam orientation in each frame. The two types of frames analyzed were; low rise building with five storeys and a high rise building with twenty storeys. The site locations for both structures were in the region of California in the United States of America. The structures were analyzed by subjecting them to two earthquakes Loma Prieta and San Fernando as they were two of the major earthquakes that struck California in the nineties.
\end{abstract}

Keywords Concentrically Braced Frames, Steel Structure, Chevron Bracing, Metallic Yielding Dampers, Energy Dissipation, Time History Analysis, ETABS

\section{Introduction}

Traditionally, structures were over designed to resist dynamic forces, as such given off from a seismic activity. These structures would be high in stiffness and strength. So during a seismic activity they would absorb this energy and then deform beyond their elastic limit. Nowadays structural protective systems are designed to prevent this from happening. These modern structural protective systems can be divided into three parts. They are seismic isolation, passive energy dissipation and semi active and active systems. [1]

This study has considered passive energy dissipation technique of metallic yielding dampers. The other types of passive energy dissipation devices are Friction dampers, Viscoelastic dampers, Tuned mass dampers and Tuned liquid dampers. These devices absorb the energy from the seismic activity and therefore reduce the dissipation of energy throughout the structure. They do not require an external power source and also cannot add energy to the structural system.

\section{Hysteretic Damping Mechanism}

Hysteresis loops are a sequence of loops in the force-displacement or resistance-deformation relationship. These are created due to successive loadings and unloading on structures. Cyclic characteristics of ground motion are considered to be the cause of these loading and unloading. When a structure is affected by a severe earthquake, the deformations experienced are beyond the elastic range. These inelastic deformations depend on the magnitude of the earthquake and also the load-deformation characteristics of the structure.

Hysteresis loops are used to measure the structure's capacity to dissipate energy. The structural stiffness and yield displacement determines the shape and orientation of the loop. Hysteretic behavior is affected by factors like structural system, structural material and type of connection [1].

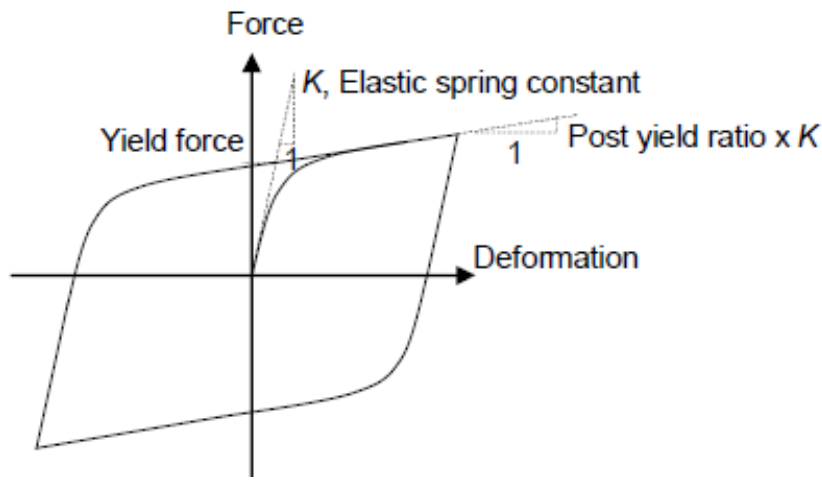

Figure 1. Bouc Wen's Plasticity Model 
In this research, metallic yielding devices that absorb energy through hysteresis were connected to the chevron bracings and the frame. The modeling of these devices were done in the panel zone using ETABS PLASTIC1 property that is based on the hysteretic uniaxial plasticity behavior proposed by Wen [1976] (Figure 1). [1]

\section{Metallic Yielding Dampers (MYD)}

The mechanism used by metallic yielding dampers to dissipate energy from a seismic activity is through hysteretic behavior which occurs during the plastic deformation of metallic components. This was first proposed by Kelly in 1972. A larger amount of the vibration energy is absorbed by the yielding of metallic structures. They are placed at selected locations of the main structure and as they are not embedded to the main structure, therefore replacement after a large seismic event is easier [2]. These damping devices must have the suitable characteristics like adequate elastic strength and stiffness so that the device does not reach inelastic region under service loads. The other characteristics include having a good capability to dissipate energy and a resistance to low cycle fatigue.

The effectiveness of the yielding devices in improving the earthquake resistance of a structure depends on the proper selection of the parameters governing their behavior. The results of numerical and analytical investigations have revealed that the key parameters involved in the design of these dampers are: the ratios of bracing stiffness to device stiffness, brace-device assemblage stiffness to device stiffness, and assemblage stiffness to that of the corresponding storey [2].

\section{Added Damping and Stiffness (ADAS)}

Added damping and stiffness devices were first studied by Whittaker. This device has a number of X-shaped plates.

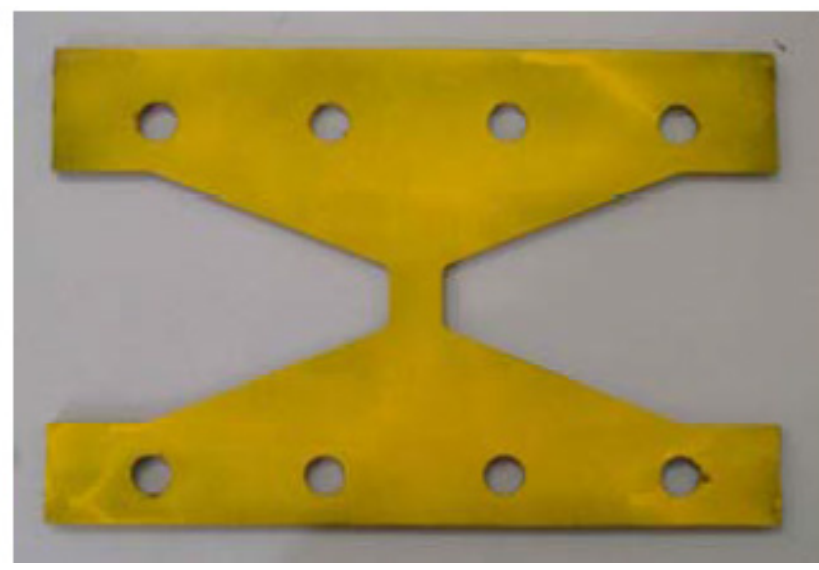

(a)
The two ADAS devices that are analyzed in this study are $\mathrm{X}$-shaped damper and Double X-shaped metallic damper. These shapes make sure that yielding occurs over the entire length of the device. ADAS devices improved the behavior of the main structure by increasing its stiffness, increasing its strength and its ability to dissipate energy [3].

ADAS have some advantages: they do not require sophisticated technology to get produced, they can easily be integrated into structures, and they show a stable behavior under the effect of the earthquake, as well as environmental factors (temperature, humidity) which do not affect their performance. These dampers are usually mounted in a frame of a bracing system. After the earthquake, they can easily be replaced for the reinforcement of the structure for future earthquakes [4].

The equations used to determine the required parameters are given below:

The initial elastic stiffness:

$$
K_{A D A S}=n\left(\frac{2 E b t^{3}}{3 h^{3}}\right)
$$

The yield force:

$$
F_{y}=n\left(\frac{\sigma_{y} b t^{2}}{2 h}\right)
$$

Where $\mathrm{n}$ is the number of plates which compose the ADAS system, $b$ is the width of the plates, $h$ the height of the plates and $\mathrm{E}$ the elasticity modulus of the material. [5]

\subsection{X-shaped Metallic Damper}

This has properties like large initial stiffness and high bearing capability. But experimental results have shown that stress concentrates in the center and the corner of the damper and experiments have also shown that bending deformation is less than stress deformation [5]. But this is the basic type of ADAS damper and we will be using this as the norm of our analysis. Figure 2(a) shows the basic geometry of a X-shaped damper while Figure 2(b) shows the hysteresis diagrams obtained from the studies done by Li \& Li, 2007.

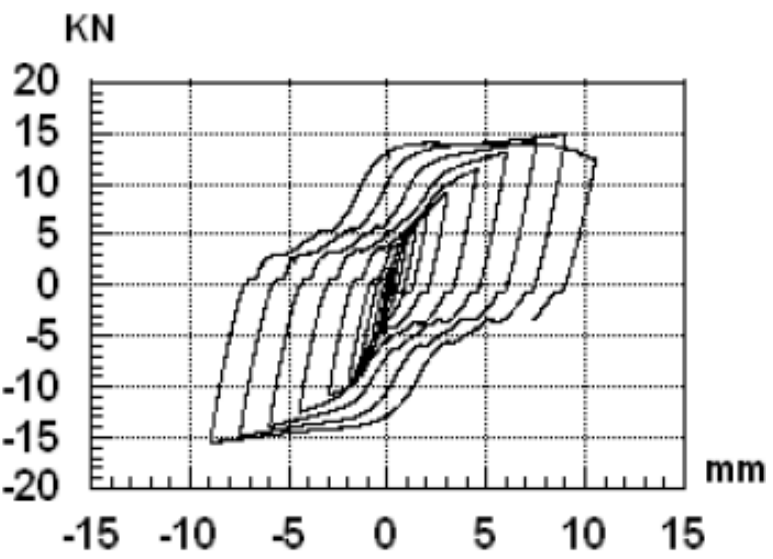

(b)

Figure 2. (a) X-shaped metallic damper (b) Hysteretic curves of X-shaped metallic damper (Li \& Li, 2007) 


\subsection{Double X-shaped Metallic Damper}

This type of damper was first proposed by $\mathrm{Li}$ and $\mathrm{Li}$ in 2008. The geometrical shape and the hysteresis curve for this is shown in Figure 3(a) and Figure 3(b) respectively. From the experiments they concluded that this damper has both large initial stiffness and energy dissipating capability. The double $\mathrm{X}$ shape makes it more resistant to buckling. [5]

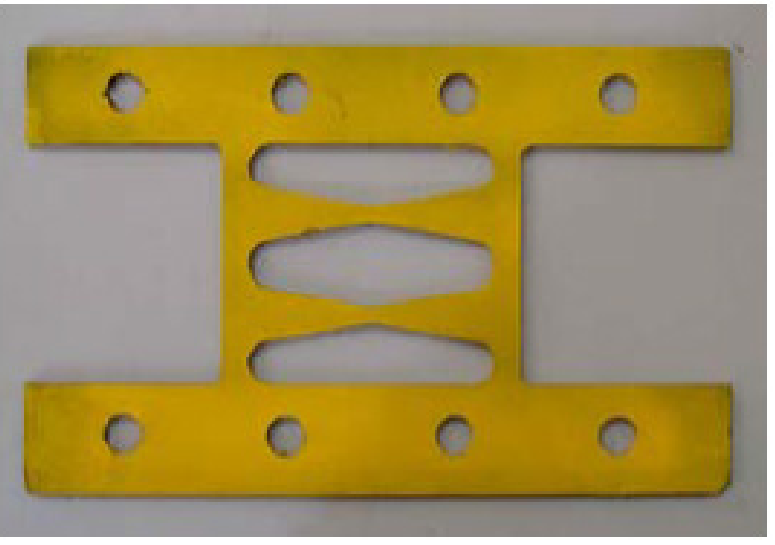

(a)

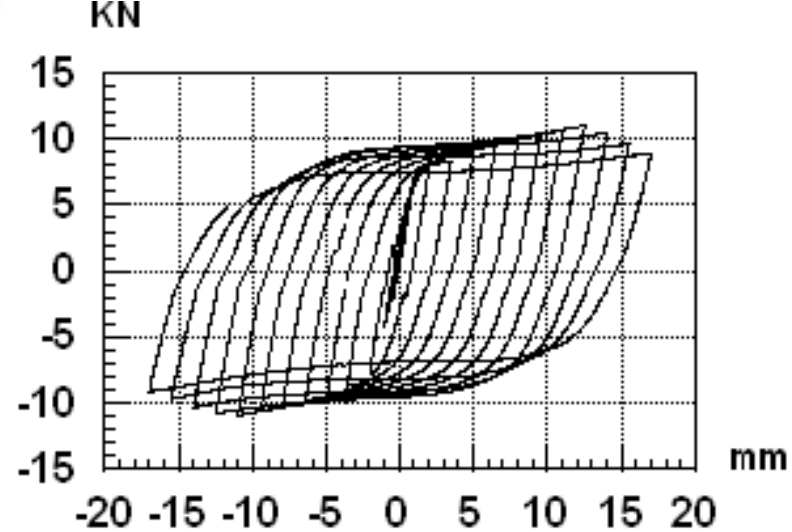

(b)

Figure 3. (a) Double X-shaped metallic damper; (b) Hysteretic curves of Double X-shaped metallic damper (Li \& Li, 2007)

\section{Comb-teeth Damper}

Comb teeth damper is a newly introduced yielding damper, which dissipates energy through in-plane flexural yielding of its teeth [6]. Figure 4(a) shows a comb teeth damper installed in a Chevron bracing while the typical geometry of a comb teeth damper is shown in Figure 4(b). The teeth or the links do not connect to each other at one end of the damper therefore each link controls their own axial and lateral deformations. They dissipate energy through flexural yielding.

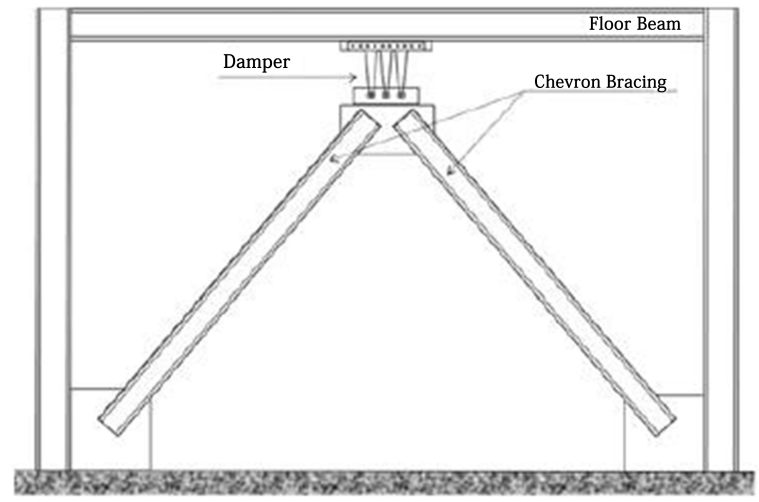

(a) Frame configuration

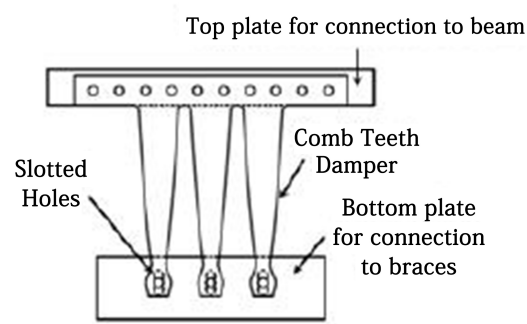

(b) components of a CTD

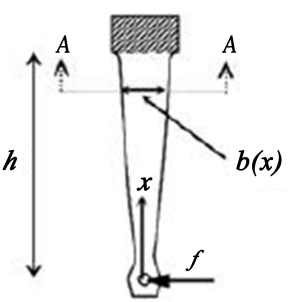

(C) Individual links of the damper

Figure 4. A typical comb teeth damper in a frame (Garivani et al., 2016)

An individual link [Figure 4(c)] connects to a T-shape section or a plate at the top, along with other individual links. At the other end, where the links connect to the braces, a steel plate is provided. The holes used are vertically aligned slotted holes. This is because standard holes hinder vertical displacement at the link ends and causes axial elongation when the damper deforms under shear load. Under reversing load histories axial compression occurs and results in bucking and failure of the links. This characteristic reduces stiffness, damping, strength and energy dissipation capacity. As there is no connection to each other at one end, the links act in parallel and each link goes through in-plane shear force when a lateral deformation is applied to the frame [6]. Figure 5 shows a few hysteretic loops of several comb teeth dampers. 


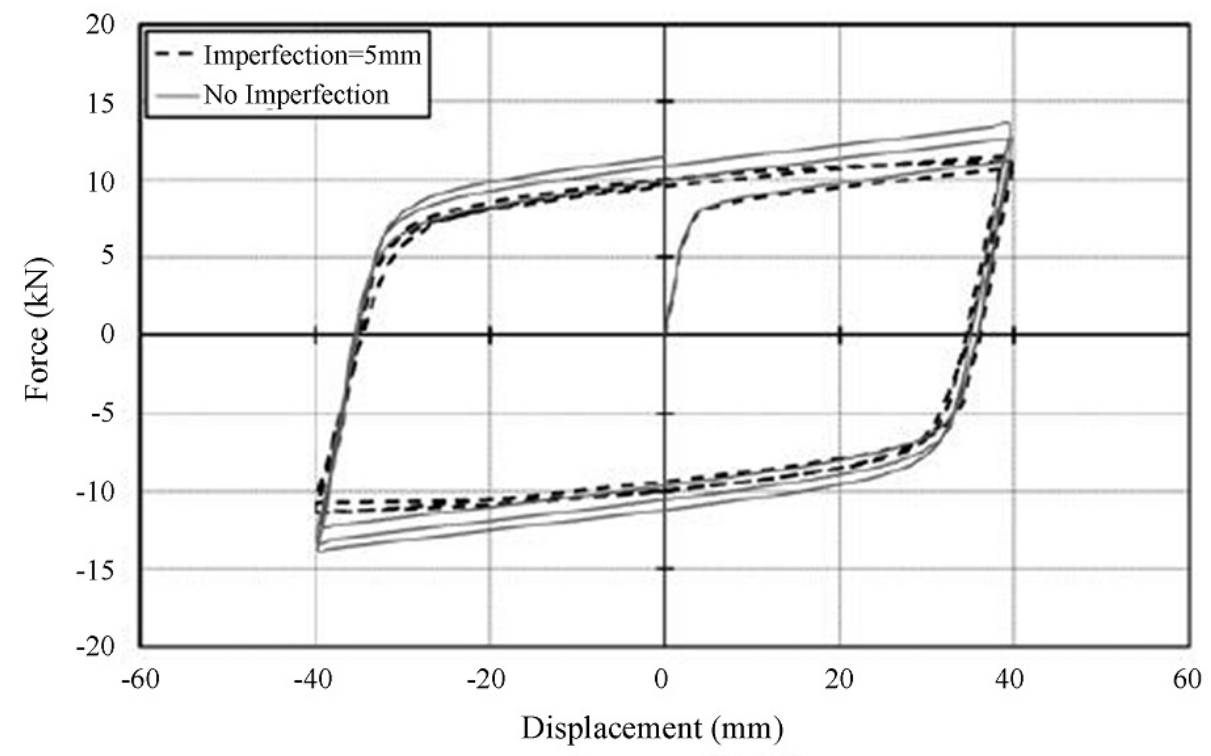

Figure 5. Hysteretic behavior of several comb teeth dampers (Garivani et al., 2016)

The elastic stiffness of an individual link is found by the following equation, [6]

$$
K_{l}^{e}=\frac{E t \lambda^{3}}{h^{\frac{3}{2}}}
$$

Where $t$ is plate thickness; $h$ is the height of the link; $E$ is elastic modulus; $\lambda$ is a constant

And also its yield strength, $f_{y}$, can be calculated as below, $\sigma_{\mathrm{y}}$ is the material yield stress;

$$
f_{y}=\frac{2}{3} t \lambda^{2} \sigma_{y}
$$

\section{Different Materials Used for MYDS}

\subsection{Aluminium 6061-T6; 6061-T651}

The shear yielding of aluminium had been found to be very ductile and very large inelastic deformations are possible without tearing or buckling [7]. The low yield strength of aluminium in shear allows the use of thicker webs which further reduces the chances of web buckling. The yielding in shear mode maximizes the material participating in plastic deformation without excessive localized strains. Table 1 shows the mechanical properties of Aluminium.

Table 1. Mechanical Properties of Aluminium 6061-T6; 6061-T651

\begin{tabular}{|c|c|}
\hline Physical Properties & Value of Property \\
\hline Ultimate Tensile Strength & $310 \mathrm{MPa}$ \\
\hline Tensile Yield Strength & $276 \mathrm{MPa}$ \\
\hline Elongation at Break & $12 \%$ \\
\hline
\end{tabular}

\subsection{High Yield Steel: A992 Steel}

A992 is a high strength, low alloy steel. Its mechanical properties are shown in Table 2. Its best applied where there is need for more strength per unit of weight. This structural steel alloy is typical used for wide flange and I beams. It has a high material ductility as it has a high yield to tensile strength ratio and is resistant to atmospheric corrosion [8].

Table 2. Mechanical Properties of A992 steel

\begin{tabular}{|c|c|}
\hline Physical Properties & Value of Property \\
\hline Ultimate Tensile Strength & $450 \mathrm{MPa}$ \\
\hline Tensile Yield Strength & $345-450 \mathrm{MPa}$ \\
\hline Elongation at Break & $21 \%$ and over \\
\hline
\end{tabular}

\subsection{Mild Yield Steel: A36 Steel}

As the dampers are passive to seismic input they should fail before any other component of the main structure does. Therefore using low yield steel is the best option for damping devices. For a large earthquake the device is going to undergo great repeated deformations in the plastic region. This shows that the device needs to be made of a material that has excellent elongation and low cycle fatigue characteristics.[8] The mechanical properties of A36 steel are shown below in Table 3 .

Table 3. Mechanical Properties of A36 Steel

\begin{tabular}{|c|c|}
\hline Physical Properties & Value of Property \\
\hline Ultimate Tensile Strength & $400-550 \mathrm{MPa}$ \\
\hline Tensile Yield Strength & $250 \mathrm{MPa}$ \\
\hline Elongation at Break & 250 \\
\hline
\end{tabular}

\section{Base Frame Modeling}

The site location for this study was chosen as Los 
Angeles, California. Throughout the study 5 storey and 20 storey ordinary base frames was analyzed. Chevron bracing (inverted V-braces with vertical slotted connections) was selected. Chevron bracing has slotted connections provide only horizontal load transfer from the braces to the beam therefore the vertical components of the brace loads become equal. Thus the brace loads are governed by the buckling resistance of the compression brace and not the member tensile strength. Also, vertical load transfers to the beam are also avoided [9].

The seismic design parameters taken for this study are given in Table 4 below:

Table 4. Seismic design Parameters (ASCE 7-10)

\begin{tabular}{|c|c|c|c|}
\hline No & Design Parameters & Symbol & Value \\
\hline 1 & Response modification coefficient for steel ordinary concentrically braced frames (Table 12.2-1 from ASCE 7-10) & $\mathrm{R}$ & 3.25 \\
\hline 2 & Over strength factor for steel ordinary concentrically braced frames (Table 12.2-1 from ASCE 7-10) & $\Omega$ & 2 \\
\hline 3 & Deflection amplification factor Steel ordinary concentrically braced frames (Table 12.2-1 from ASCE 7-10) & $\mathrm{C}_{\mathrm{d}}$ & 3.25 \\
\hline 4 & Seismic importance factor for building with substantial risk to human life in event of failure (Table 1.5-2 from ASCE 7-10) & I & 1.25 \\
\hline 5 & $\begin{array}{l}\text { Mapped MCER, } 5 \text { percent damped, spectral response acceleration parameter at short period based on the site location } \\
\text { (Section 11.4.1 of ASCE 7-10) }\end{array}$ & $\mathrm{S}_{\mathrm{s}}$ & $2.042 \mathrm{~g}$ \\
\hline 6 & $\begin{array}{l}\text { Mapped MCER, } 5 \text { percent damped, spectral response acceleration parameter at a period based on the site location (Section } \\
\text { 11.4.1 of ASCE 7-10) }\end{array}$ & $\mathrm{S}_{1}$ & $0.843 \mathrm{~g}$ \\
\hline 7 & Long-Period transition period based on the site location (Section 11.4.5 of ASCE 7-10) & $\mathrm{T}_{\mathrm{L}}$ & 8 \\
\hline 8 & Soil type of the location site class C used for very dense soil or soft rock. (Section 11.4.2 of ASCE 7-10) & $\mathrm{SC}$ & $\mathrm{C}$ \\
\hline
\end{tabular}

The assignment of loads along with gravity loads were done according to ASCE 7-10. The ASCE 7-10 linear static load of $1.2 \mathrm{D} \pm 0.5 \mathrm{~L} \pm 1.0 \mathrm{E}$ was used where $\mathrm{D}=$ Dead Load, $\mathrm{L}=$ Live Load \& $\mathrm{E}=$ Earthquake Load. Table 5 shows the characteristics of frames that were designed.

Table 5. Characteristics of the frame

\begin{tabular}{|c|c|c|c|c|c|c|c|c|}
\hline Frame Name & Building Type & No. of Stories & No. of Bays & Bay Size & Storey Height & Dead Load & Live Load & Material \\
\hline CB05 & Office & 05 & 3 & $24 \mathrm{ft}$ & $\begin{array}{c}15 \mathrm{ft}(\mathrm{base}) \\
12 \mathrm{ft}\end{array}$ & Self-Weight $+60 \mathrm{psf}$ & $\begin{array}{c}50 \mathrm{psf} \\
\mathrm{Al} \\
\mathrm{A} 36 \\
\mathrm{~A} 992\end{array}$ \\
\hline CB20 & Office & 20 & 3 & $24 \mathrm{ft}$ & $\begin{array}{c}15 \mathrm{ft}(\mathrm{base}) \\
12 \mathrm{ft}\end{array}$ & Self-Weight $+60 \mathrm{psf}$ & $\begin{array}{c}50 \mathrm{psf} \\
\mathrm{A}\end{array}$ \\
$\begin{array}{c}\mathrm{A} 36 \\
\mathrm{~A} 992\end{array}$ \\
\hline
\end{tabular}

ETABS 2013 software was used for the modelling and analysis of the above mentioned frames. Figures 6 and 8 shows the two base frames ( 5 storey and 20 storey) with section properties while Figure 7 shows load assignments, with Chevron bracing.

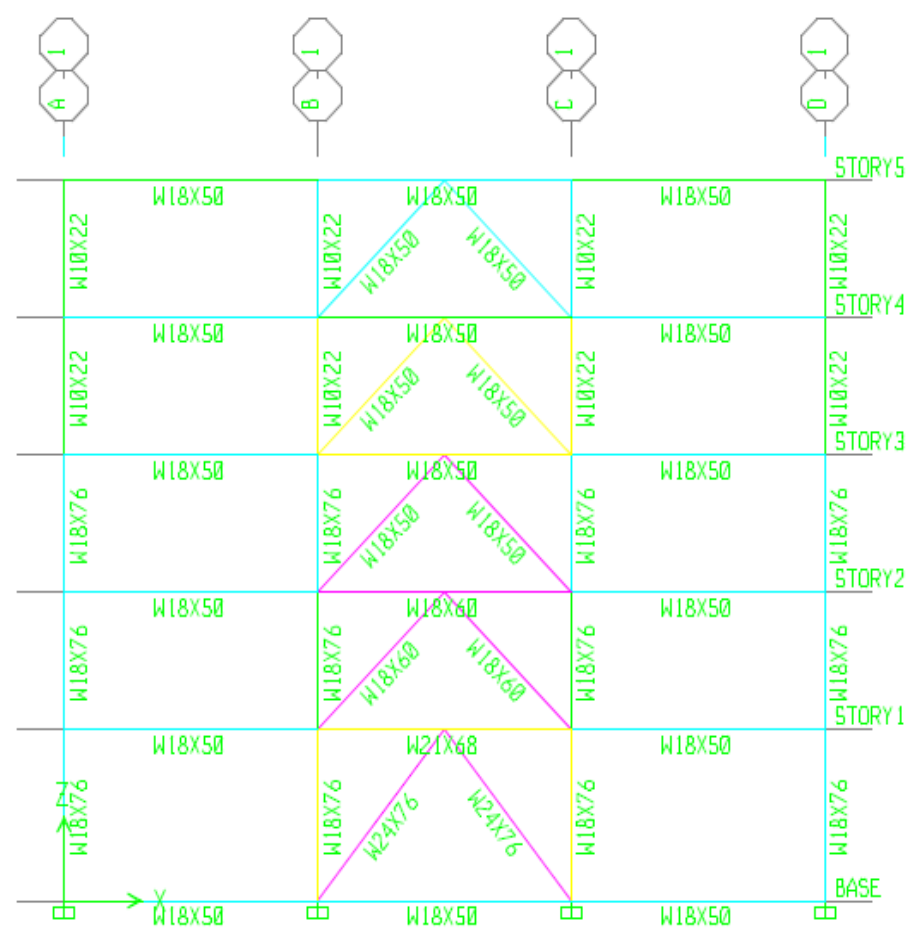

Figure 6. Structural model for 5-storey building 


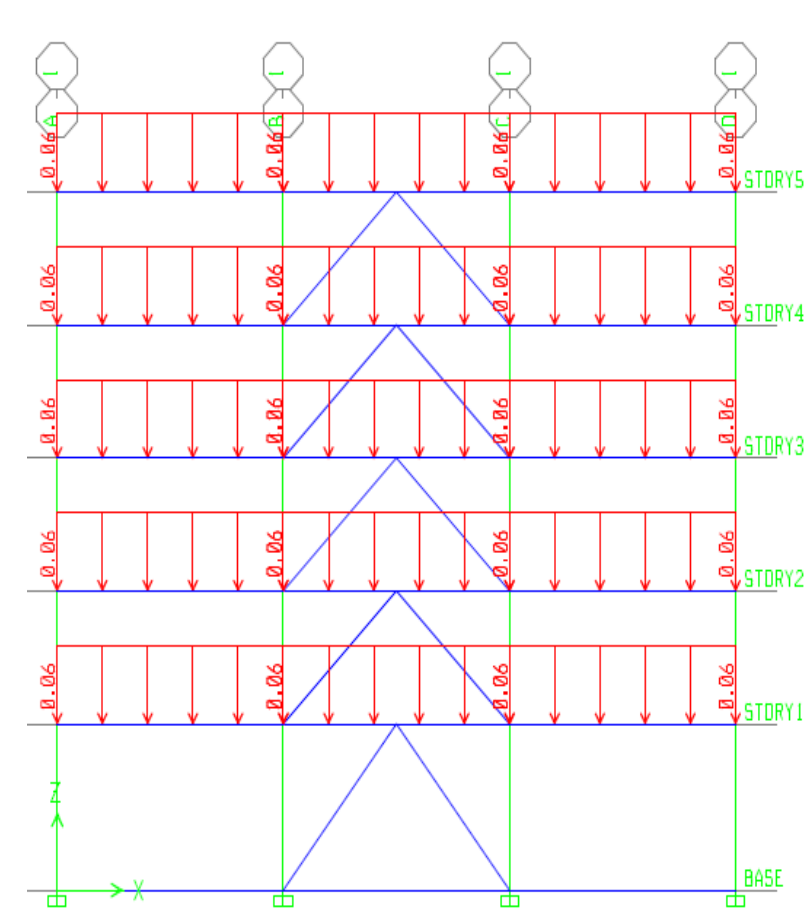

(a)

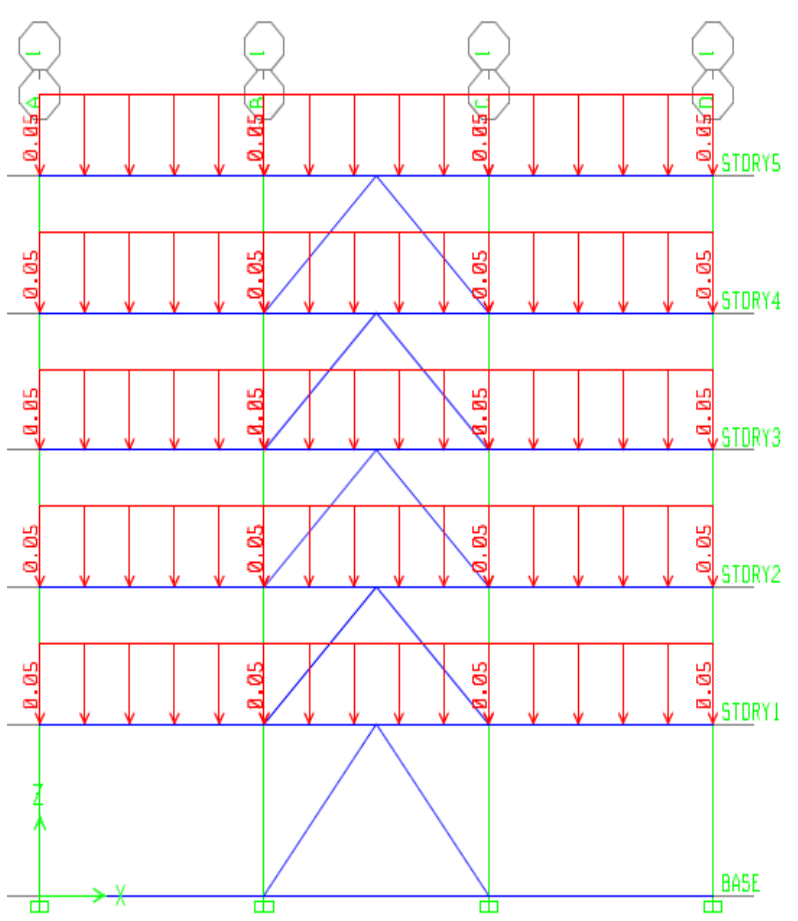

(b)

Figure 7. Load distribution on 5-storey building (a) Dead load (b) Live load

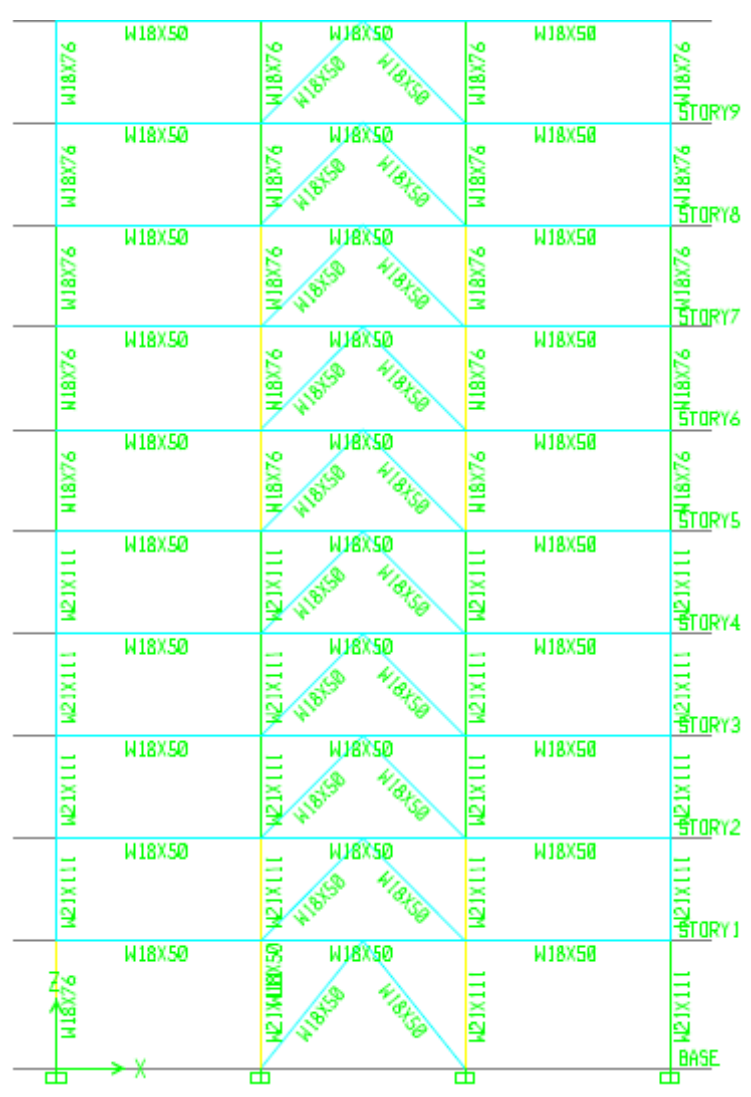

(a)

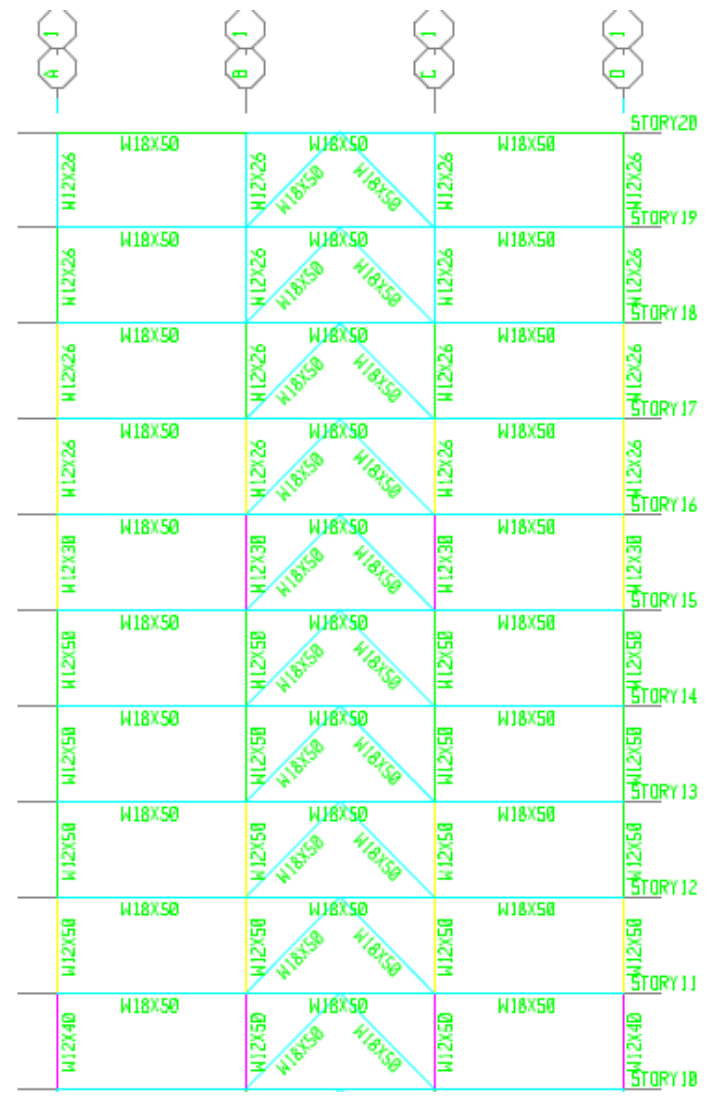

(b)

Figure 8. Structural model for 20 -storey building 


\section{Application of Seismic Ground Motion}

Time history data was applied after finishing the base modeling process. The time history data was obtained from Pacific Earthquake Engineering Research (PEER) database (Table 6). These data was then converted to response spectrum curves by Fast Fourier transformation. This conversion was done using PRISM computer software. Then time histories were scaled to meet the requirement of the design spectrum according to ASCE 7-10.

Table 6. Earthquake Data (PEER, 2015)

\begin{tabular}{|c|c|c|c|c|c|}
\hline Earthquake Name & Year & Magnitude & PGA & Frequency (Hz) & Label \\
\hline Loma Prieta & 1989 & 6.93 & $0.2435 \mathrm{~g}$ & $0.4-1.0$ & LP \\
\hline San Fernando & 1971 & 6.60 & $1.25 \mathrm{~g}$ & 11.23 & SF \\
\hline
\end{tabular}

To calculate the period of the structure the following equation was used;

$$
T=C_{t} h_{n}^{x}
$$

Values for coefficient $C_{t}=0.02$ and $x=0.75$ values and $h_{n}$ is the structural height. These values were obtained according from ASCE 7-10 for moment resist frame systems. Table 7 shows the values obtained from the above equation.

Table 7. Time periods for 5 and 20 storey frames

\begin{tabular}{|c|c|c|c|c|c|}
\hline \multicolumn{3}{|c|}{5 Storey } & \multicolumn{3}{c|}{ 20 Storey } \\
\hline $\mathrm{T}$ & $0.2 \mathrm{~T}$ & $1.5 \mathrm{~T}$ & $\mathrm{~T}$ & $0.2 \mathrm{~T}$ & $1.5 \mathrm{~T}$ \\
\hline 0.447 & 0.089 & 0.671 & 1.231 & 0.246 & 1.846 \\
\hline
\end{tabular}

\section{Application of Dampers to the Base Frame}

Each damper; X-shaped, Double X-shaped and Comb teeth damper, was applied to each of the designed brace frames. To do this ETABS was provided with stiffness and yielding parameters of each damper type. Initially, link elements (nonlinear dynamic properties) were defined. Then, to assign dampers, panel zones were used. The time history functions were applied to each case and analyzed by ETABS.

Damper properties like effective stiffness and yield force for each material; A992 steel, A36 steel and aluminium were calculated and input in ETABS when the link elements were defined. Each property was calculated for different number of plates. This information is given Tables 8, 9 and 10 .

\section{Calculated Non-linear Damper Properties}

Effective stiffness and yield force for each damper type for three types of material was calculated according to the equations mentioned. The number of plates for each damper was varied in order to observe its effect to the performance of the damper. Tables 8, 9 and 10 give the calculated non-linear damper properties for X-shaped, DX-shaped and comb teeth damper respectively.

Table 8. Calculated Effective and Yield force Values (X-Shaped damper)

\begin{tabular}{|c|c|c|c|c|c|c|c|c|c|}
\hline \multirow{2}{*}{ Non-Linear Property } & \multicolumn{3}{|c|}{ A992 } & \multicolumn{3}{c|}{ A36 } & \multicolumn{3}{c|}{ Aluminium } \\
\cline { 2 - 11 } & 5 plates & 8 plates & 10 plates & 5 plates & 8 plates & 10 plates & 5 plates & 8 plates & 10 plates \\
\hline Damper Name & X-5-A992 & X-8-A992 & X-10-A992 & X-5-A36 & X-8-A36 & X-10-A36 & X-5-AL & X-8-AL & X-10-AL \\
\hline Effective Stiffness (N/mm) & 8533.3 & 13653.6 & 17066 & 8533.3 & 13653.6 & 17066 & 2939.75 & 4703.6 & 5879 \\
\hline Yield Force (N) & 27600 & 44160 & 55200 & 20000 & 32000 & 40000 & 22080 & 35328 & 44160 \\
\hline
\end{tabular}

Table 9. Calculated Effective and Yield force Values (DX-Shaped damper)

\begin{tabular}{|c|c|c|c|c|c|c|c|c|c|}
\hline \multirow{2}{*}{ Non-Linear Property } & \multicolumn{3}{|c|}{ A992 } & \multicolumn{3}{c|}{ A36 } & \multicolumn{3}{c|}{ Aluminium } \\
\cline { 2 - 11 } & 5 plates & 8 plates & 10 plates & 5 plates & 8 plates & 10 plates & 5 plates & 8 plates & 10 plates \\
\hline Damper Name & DX-5-A992 & DX-8-A992 & DX-10-A992 & DX-5-A36 & DX-8-A36 & DX-10-A36 & DX-5-AL & DX-8-AL & DX-10-AL \\
\hline Effective Stiffness (N/mm) & 8533.3 & 13653.6 & 17066 & 8533.3 & 13653.6 & 17066 & 2939.75 & 4703.6 & 5879 \\
\hline Yield Force (N) & 27600 & 44160 & 55200 & 20000 & 32000 & 40000 & 22080 & 35328 & 44160 \\
\hline
\end{tabular}


Table 10. Calculated Effective and Yield force Values (CT damper)

\begin{tabular}{|c|c|c|c|c|c|c|c|c|c|}
\hline \multirow{2}{*}{ Non-Linear Property } & \multicolumn{4}{|c|}{ A992 } & \multicolumn{3}{c|}{ A36 } & \multicolumn{3}{c|}{ Aluminium } \\
\cline { 2 - 11 } & 3 plates & 5 plates & 8 plates & 3 plates & 5 plates & 8 plates & 3 plates & 5 plates & 8 plates \\
\hline Damper Name & CT-3-A992 & CT-5-A992 & CT-8-A992 & CT-3-A36 & C -5-A36 & CT-8-A36 & CT-3-AL & CT-5-AL & CT-8-AL \\
\hline Effective Stiffness (N/mm) & 35007 & 58345 & 93352 & 35007 & 58345 & 93352 & 12060 & 20100 & 32160 \\
\hline Yield Force (N) & 42261 & 70435 & 112696 & 30624 & 51040 & 81664 & 33810 & 56350 & 90160 \\
\hline
\end{tabular}

\section{Results and Discussion}

\subsection{Five Storey Analysis}

The storey shear graphs obtained for the 5 storey frame for Loma Prieta and San Fernando earthquakes respectively for $\mathrm{X}$-shaped damper DX-shaped damper and Comb teeth damper are shown below in Figures 9, 10 and 11. The 5 storey frame without any dampers was also analyzed under the time histories to understand how the dampers work. This is shown from the dotted line in the graph.

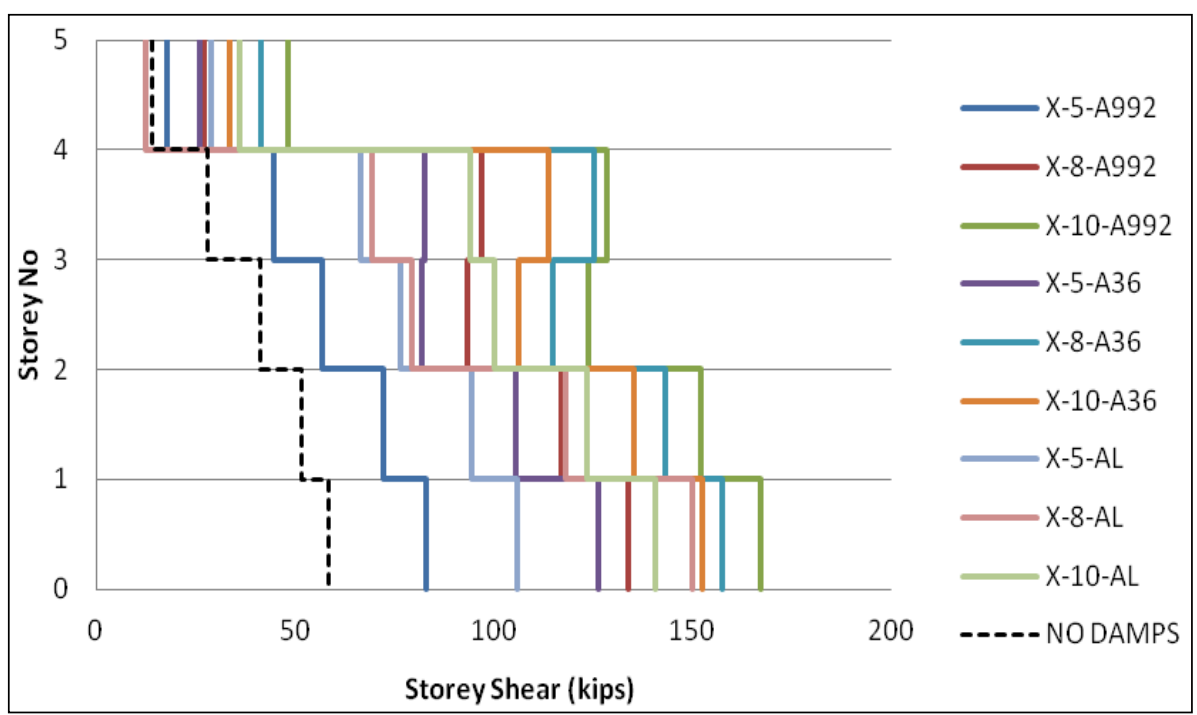

(a)

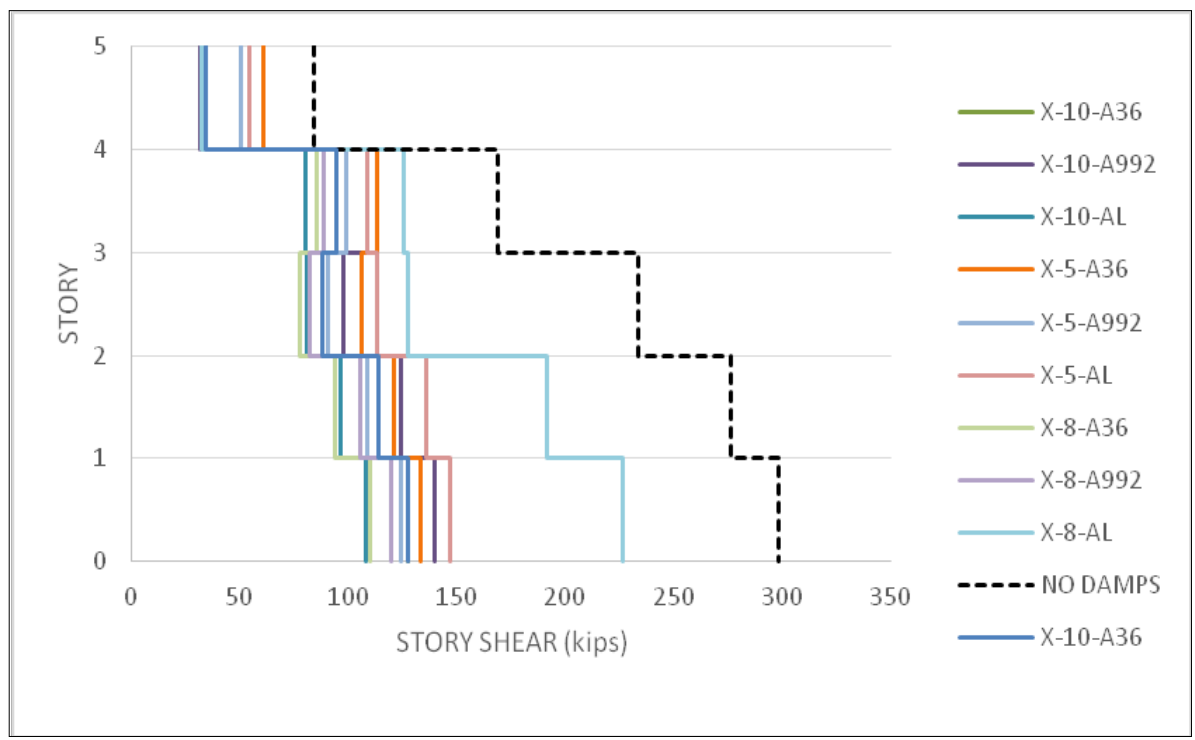

(b)

Figure 9. Shear displacement graphs for X-shaped damper under (a) Loma Prieta (b) San Fernando excitation 


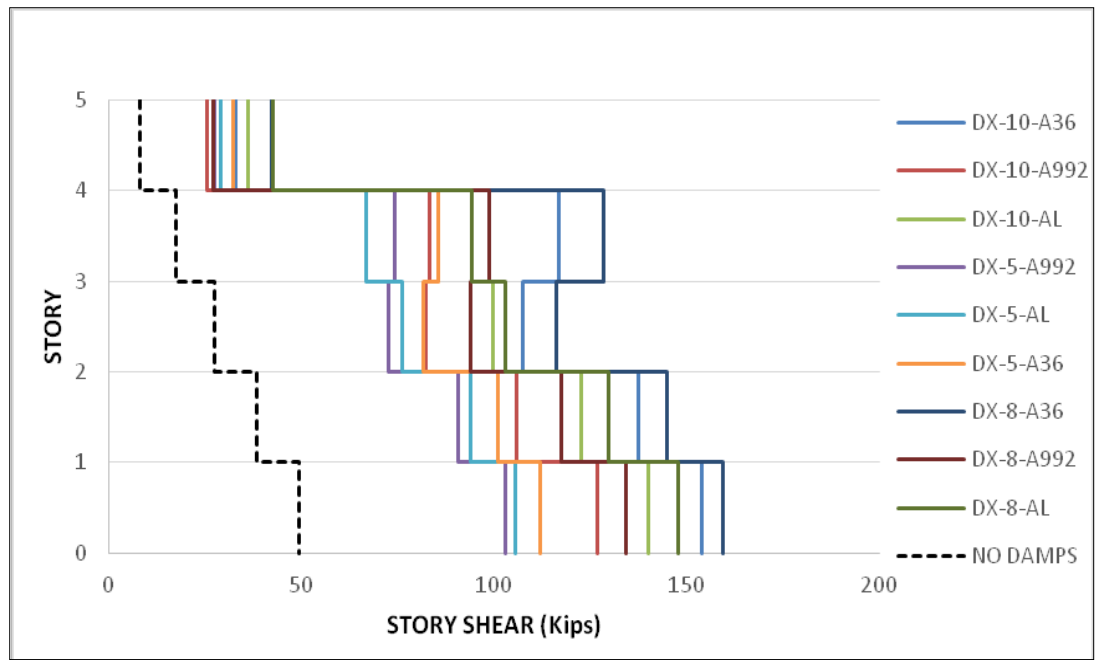

(a)

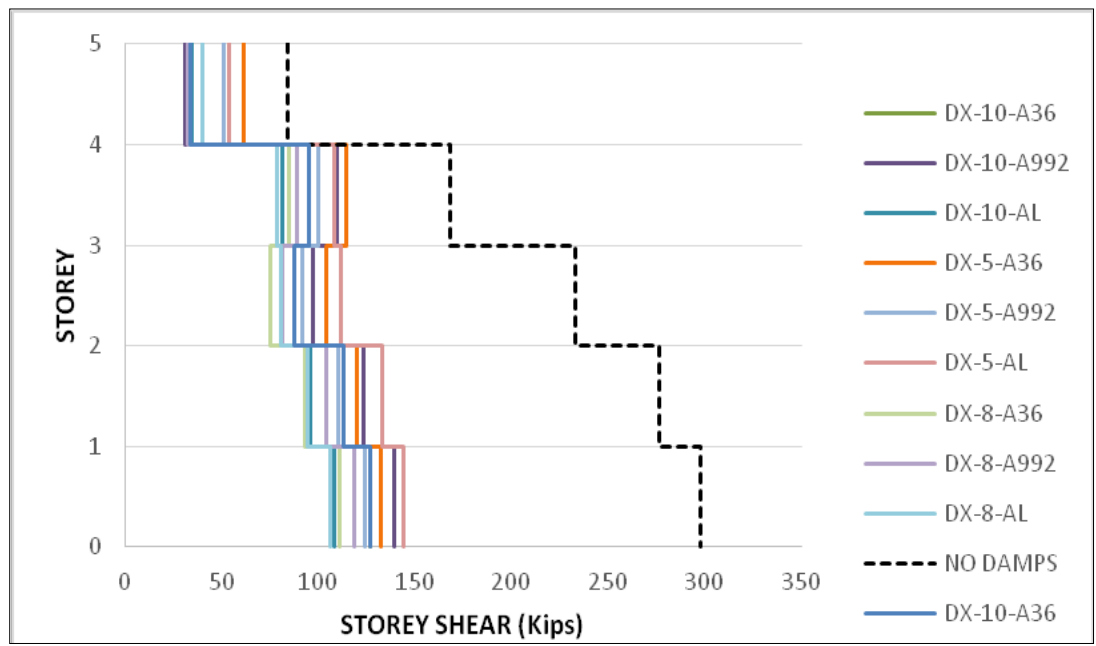

(b)

Figure 10. Shear displacement graphs for DX damper under (a) Loma Prieta (b) San Fernando excitation

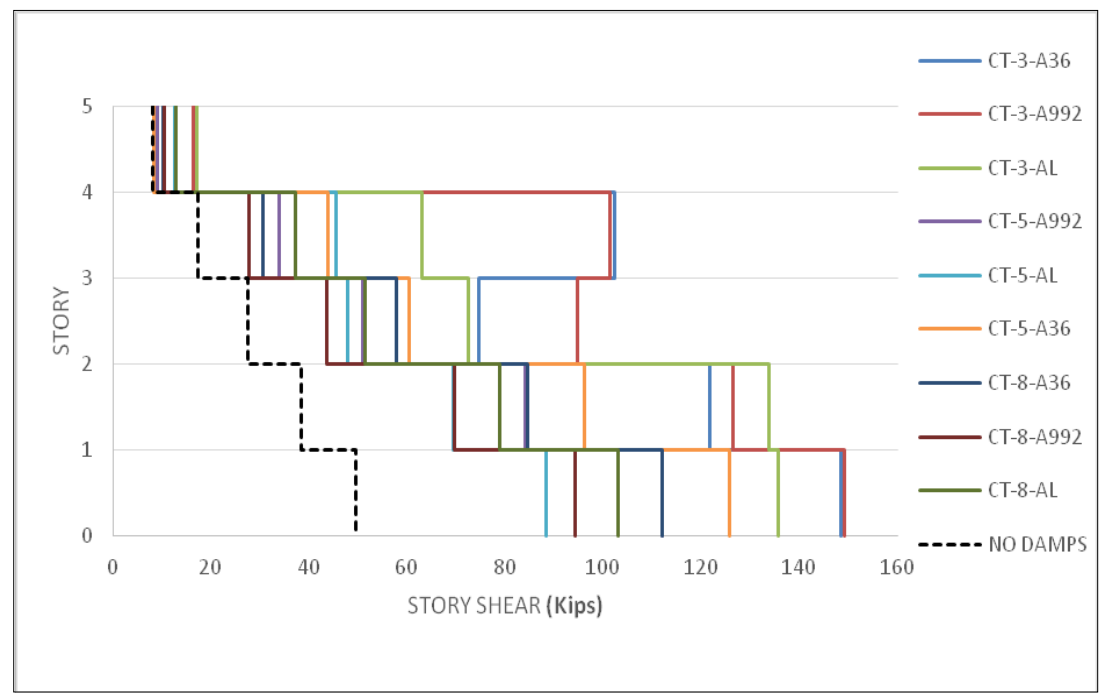




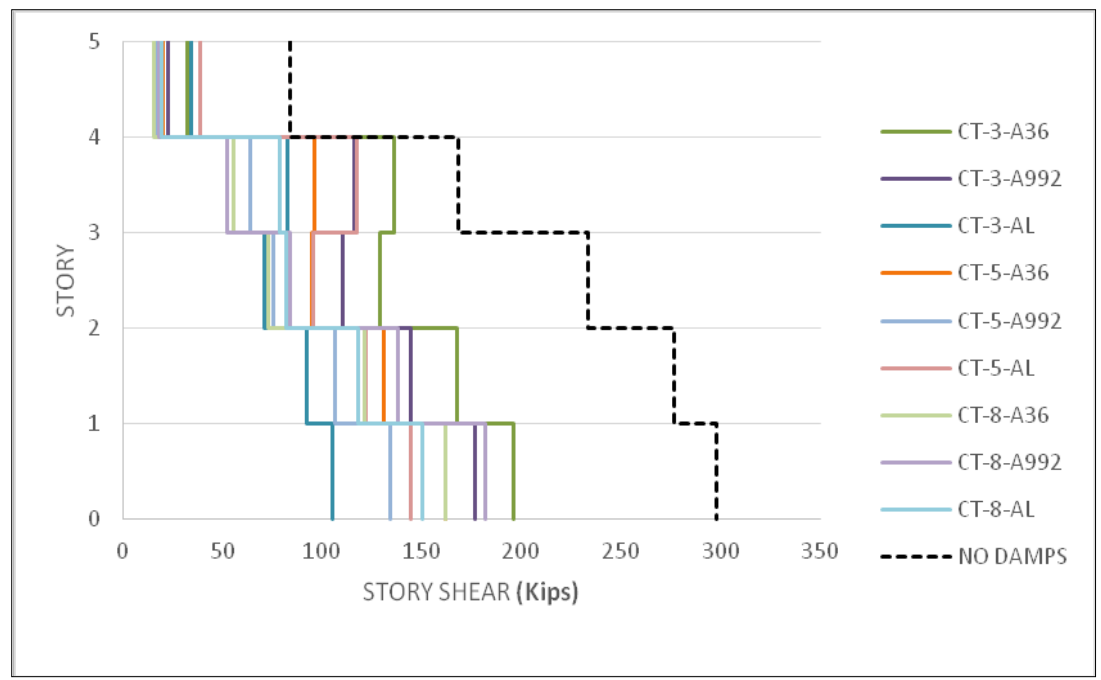

(b)

Figure 11. Shear displacement graphs for Comb teeth damper under (a) Loma Prieta (b) San Fernando excitation

The above analysis results shows that both ADAS and Comb teeth dampers performed poorly when subjected to a low frequency earthquake, like the Loma Prieta earthquake. Previous studies have shown that low rise buildings are not greatly affected by low frequency earthquakes. This is due to the phenomenon known as resonance. Therefore, the reason for both dampers to show reduced performance, when subjected to the Loma Prieta excitation, is due to the insignificant motion of the building failing to activate the dampers.

When compared to the results from the Loma Prieta excitation, the results from the San Fernando excitation show better performance of both damper types. The displacement graphs above clearly show the dampers responding very well to San Fernando excitation in contrast to Loma Preita. The storey shear values of the frames with the dampers have a lesser value compared to the storey shear values of the frame without any dampers.

When discussing the results from the three types of materials; both ADAS type dampers and comb teeth damper made from aluminium show better performance than dampers made from A992 and A36 steel. ADAS dampers with higher number of plates have a better performance. It can also be seen that the performance of the dampers are higher for comb teeth dampers with less number of teeth.

\subsection{Twenty Storey Analysis}

Same as the 5 storey analysis the same time histories were applied to a 20 storey frame. Storey shear graphs were obtained for X-shaped damper, DX-shaped damper and Comb teeth damper (Figure 12, 13, 14). Here too, a 20 storey frame without any dampers was analyzed under the time histories to understand how the dampers work.

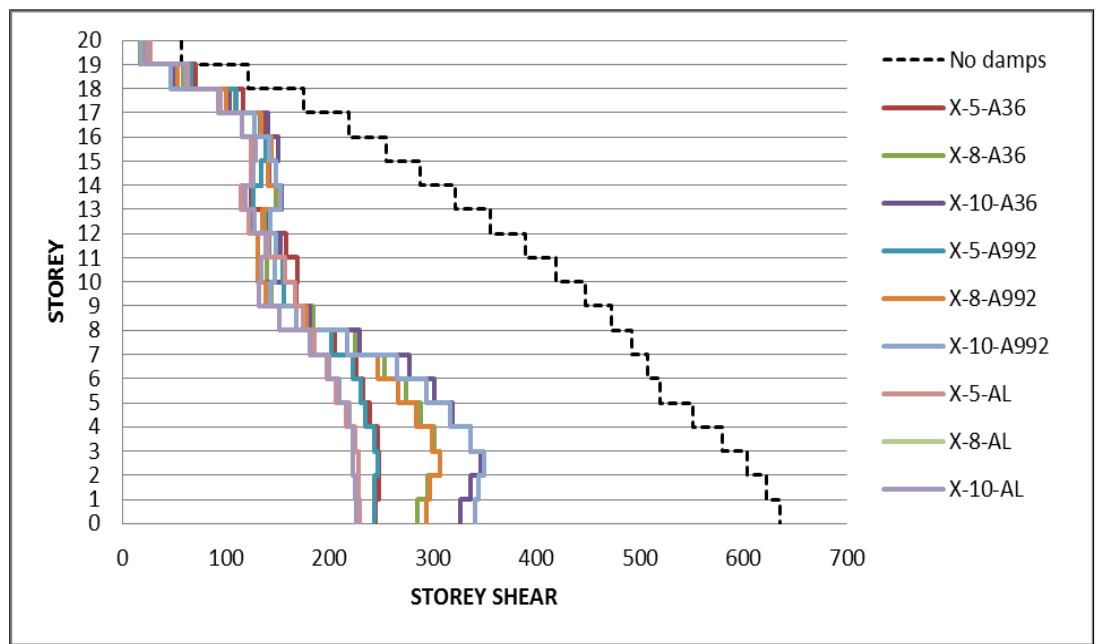

(a) 


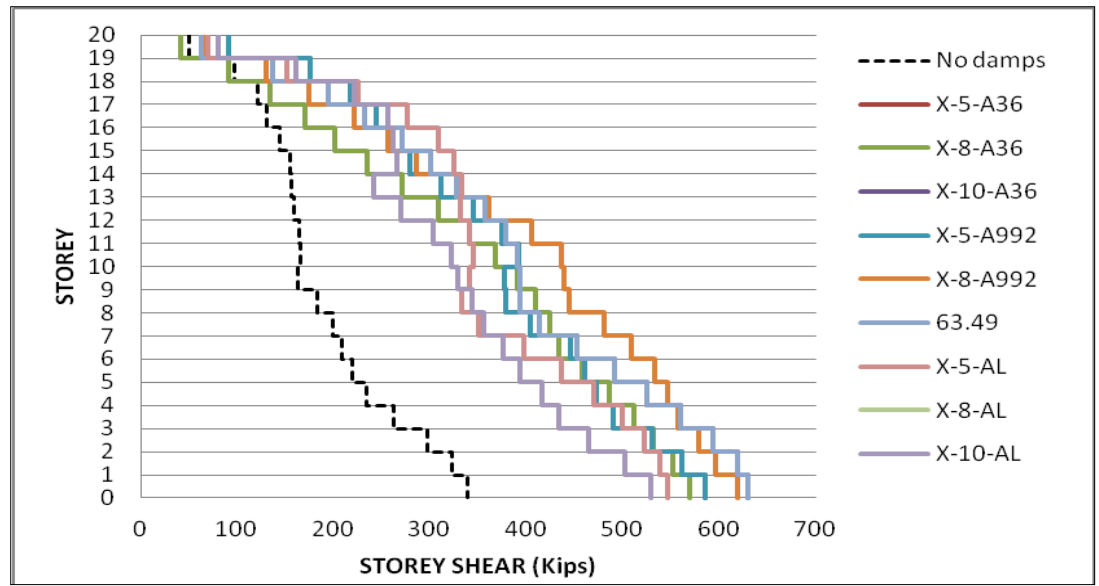

(b)

Figure 12. Shear displacement graphs for X-shaped damper under (a) Loma Prieta (b) San Fernando excitation

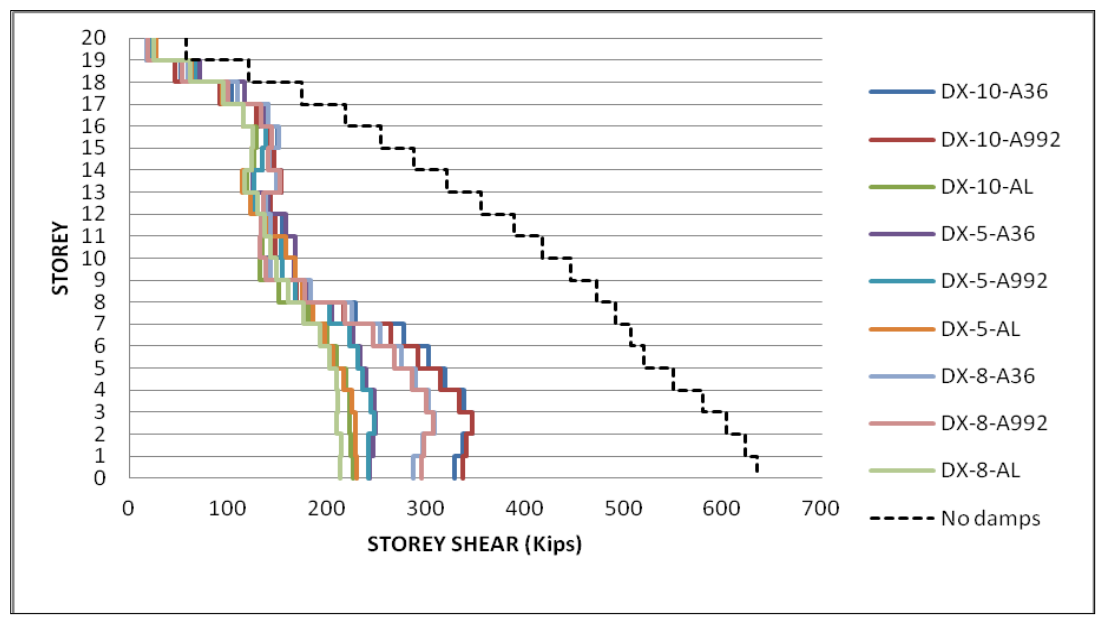

(a)

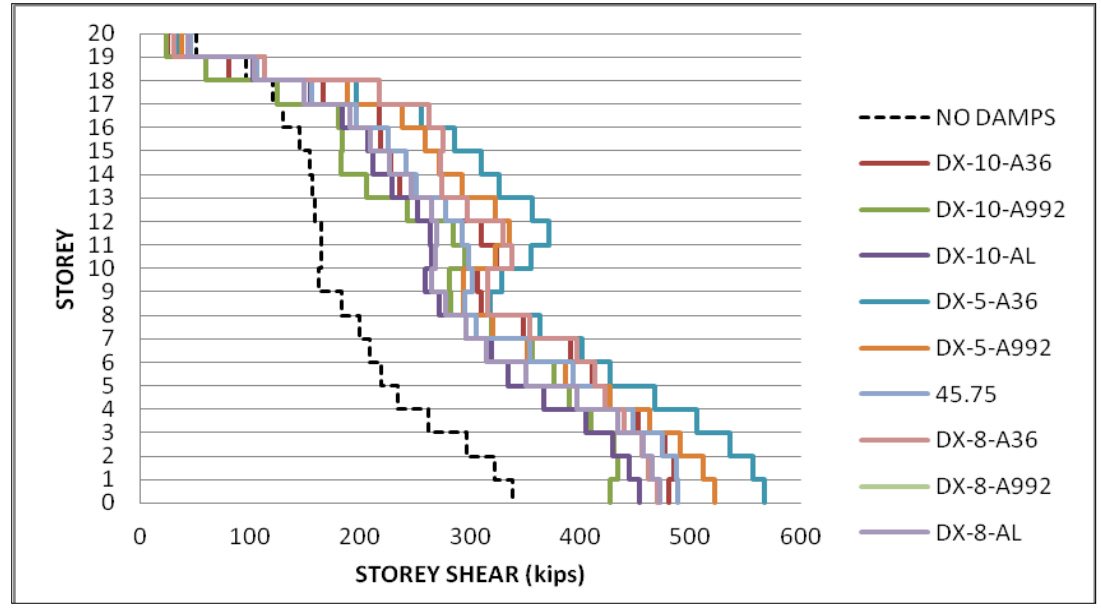

(b)

Figure 13. Shear displacement graphs for DX damper under (a) Loma Prieta (b) San Fernando excitation 


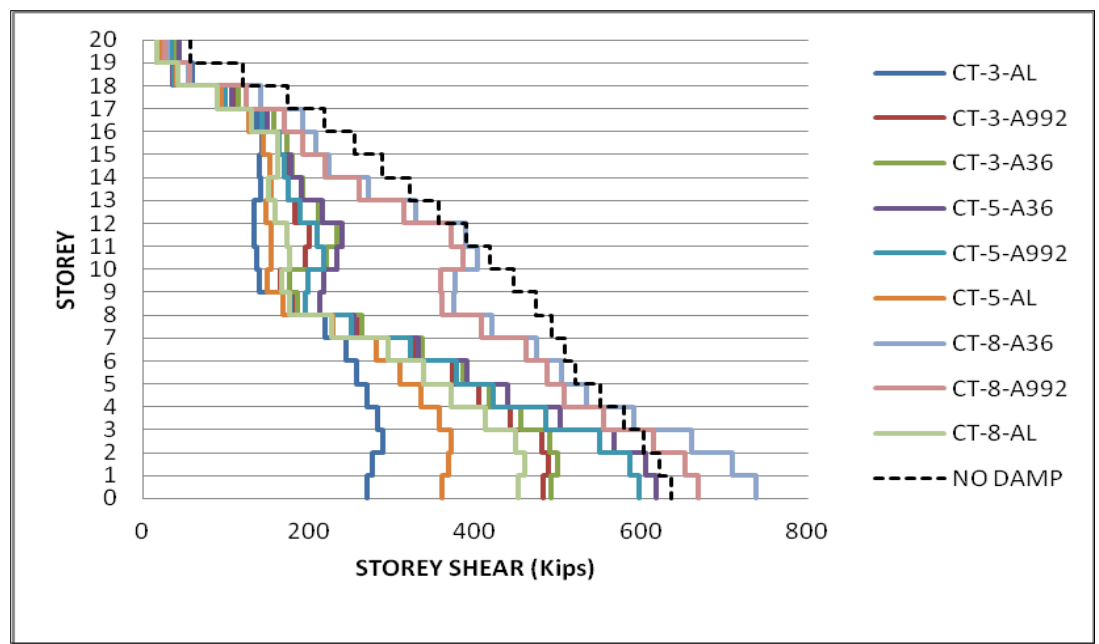

(a)

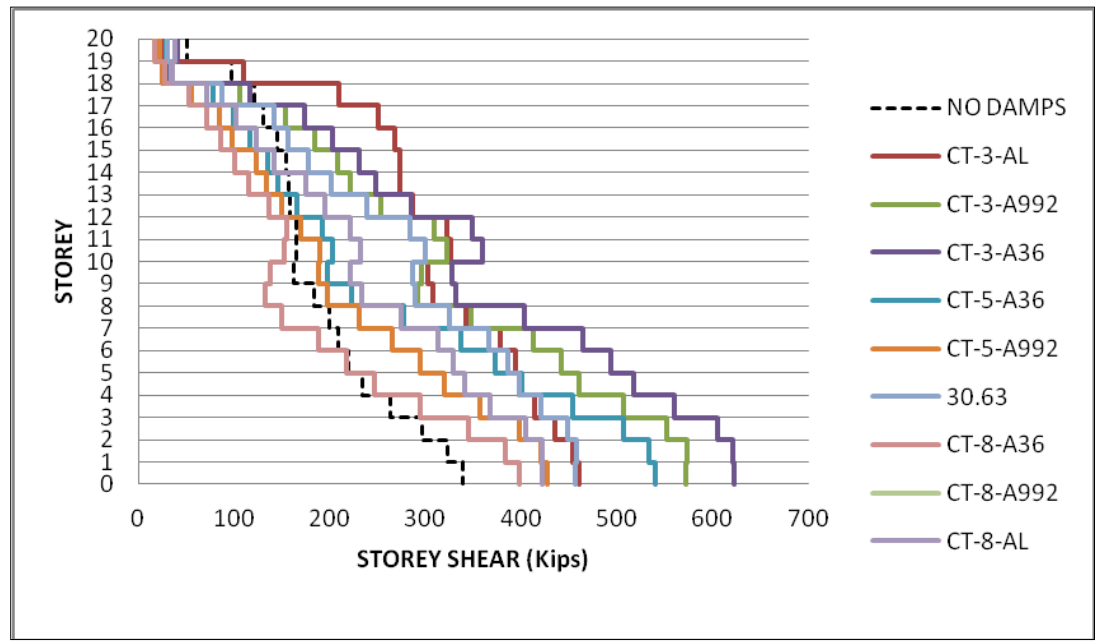

(b)

Figure 14. Shear displacement graphs for Comb teeth damper under (a) Loma Prieta (b) San Fernando excitation

The results for twenty storey analysis compliments the results obtained from the five storey analysis. Here, it can be seen that the dampers do not perform well under San Fernando excitation. This is because high frequency earthquakes do not affect high rise buildings severely. High rise buildings are most affected by low frequency earthquakes therefore the frame's motion is sufficient to activate the dampers. Both damper types show better performance under Loma Prieta excitation, which has a low frequency. The storey shear values shown in the above graphs confirm this statement.

Same as in the five storey analysis ADAS dampers with 10 and 8 plates shows better performance than the dampers with 5 plates. The performance of ADAS dampers made of steel; A992 and A36, showed better performance than dampers made of aluminium.

Comb teeth dampers with less number of teeth shows better performance than the ones with more. Compared to the performance shown by steel comb teeth damper, comb teeth dampers made from aluminium shows better performance.

\section{Conclusions}

In conclusion, the analyses done for 5 storey and 20 storey shows that both ADAS and Comb teeth dampers perform well when subjected to both high frequency and low frequency earthquakes. ADAS dampers made from steel performed better than the other ADAS dampers. For the two ADAS type dampers the performance level was high for higher number of plates.

Comb teeth dampers made from aluminium showed better results than dampers made from steel. It was observed that the number of teeth affected the performance of these dampers. The lesser the number of teeth, the better the performance will be.

Since the geometry and the yielding parameters of the two damper types; ADAS and Comb teeth are different from each other, it would be difficult and unfair to compare each other. 
From this research we understood that both dampers work efficiently under seismic activity. As from the previous researches done for ADAS, this research too proves its efficiency. Coupled with its manufacturing easiness, ADAS dampers can be further researched to achieve higher performance levels. Compared to ADAS dampers, Comb teeth dampers are a quite new introduction. So this research looks into its performance as well and any future research can develop from the results obtained.

Overall conclusion is that both dampers are efficient and shows great promise in making structures safer from seismic activity in the future.

\section{REFERENCES}

[1] Maneetes, H. (2007). Development of a Seismic Dissipating Mechanism for Precast Concrete Cladding Panels. Architectural Engineering.

[2] Benavent-climent, A. (2010). A brace-type seismic damper based on yielding the walls of hollow structural sections. Engineering Structures, 32(4), 1113-1122. https://doi.org/10.1016/j.engstruct.2009.12.037

[3] Whittaker, A. S., Bertero, V. V., José Luis Alonso G., \& Thompson, C. (1989). Earthquake simulator testing of steel plate added damping and stiffness elements (Vol. 89, No. 2).
Earthquake Engineering Research Center, University of California at Berkeley.

[4] Rais, S., Ounis, O., \& Chebili, R. (2013). Study And Modelling Of Dynamic Behaviour Of Structures With Energy Dissipation Devices Type Adas, (2011), 1-10.

[5] Li, H., \& Li, G. (2007). Experimental study of structure with " dual function " metallic dampers, 29, 1917-1928. https://doi.org/10.1016/j.engstruct.2006.10.007

[6] Garivani, S., Aghakouchak, A. A., \& Shahbeyk, S. (2016). Numerical and experimental study of comb-teeth metallic yielding dampers. International Journal of Steel Structures, 16(1), 177-196

[7] Summers, P. T., Chen, Y., Rippe, C. M., Allen, B., Mouritz, A. P., Case, S. W., \& Lattimer, B. Y. (2015). Overview of aluminum alloy mechanical properties during and after fires. Fire Science Reviews, 4(1), 3. https://doi.org/10.1186/s40038-015-0007-5

[8] Segui, W. T. (2007). Design of Steel Structures. Cengage Learning. A very good US textbook for the fundamentals of structural steel design and discusses all basic materials to be covered in this course. Albeit, design solutions refer to LRFD and ASD code provisions of American Institute of Steel Construction (AISC).

[9] Bubela, R. K. (2003). An Experimental and analytical study of chevron braced frames with vertical slotted connections (T). Retrieved from https://open.library.ubc.ca/cIRcle/collections/831/items/1.0 063804 . 